\title{
Extended neochord weaving technique for degenerative mitral valve disease
}

Taichi Sakaguchi, MD, Toshinori Totsugawa, MD, Kentaro Tamura, MD, and Hidenori Yoshitaka, MD, Okayama, Japan

From the Department of Cardiovascular Surgery, The Sakakibara Heart Institute of Okayama, Okayama, Japan. Disclosures: Authors have nothing to disclose with regard to commercial support.

Received for publication June 2, 2016; revisions received Aug 1, 2016; accepted for publication Aug 6, 2016; available ahead of print Sept 17, 2016.

Address for reprints: Taichi Sakaguchi, MD, Department of Cardiovascular Surgery, The Sakakibara Heart Institute of Okayama, 2-5-1 Nakai-cho, Kita-ku, Okayama City, Okayama 700-0804, Japan (E-mail: ts472@tuba. ocn.ne.jp).

J Thorac Cardiovasc Surg 2016;152:1626-8

$0022-5223 / \$ 36.00$

Copyright (C) 2016 by The American Association for Thoracic Surgery

http://dx.doi.org/10.1016/j.jtcvs.2016.08.017

Video clip is available online.

Despite the fact that neochordal replacement with expanded polytetrafluoroethylene (e-PTFE) has become an established technique for mitral valve repair, a number of challenges remain, particularly regarding the determination of proper neochordae length. We describe a simple and effective method for neochordal replacement.

\section{OPERATIVE TECHNIQUE}

After confirmation of the prolapsing segments, doublearmed e-PTFE (CV-5) mattress sutures reinforced with a pledget are placed onto the corresponding papillary muscle. The sutures are not tied, and 2 arms of each neochord are woven into the prolapsing leaflet with several bites from the free edge to the mitral annulus. A true sized annuloplasty ring is then sutured to the annulus, and the neochordae are passed through the corresponding part of the ring. Next, a water injection test is performed. With the ventricle filled with water, both arms of the neochordae are slowly pulled against the annuloplasty ring until the valve is fully competent. Finally, the sutures are secured by tying with multiple knots (Figure 1 and Video 1). For cases with isolated P2 prolapse, 2 neochordae are implanted into the anterior and posterior papillary muscles, without crossing the midline. For P1 or P3 prolapse cases, a single neochord is generally adequate.

We have used our technique in 10 patients with isolated posterior leaflet prolapse with successful early results.

Institutional Review Board approval was obtained for this study.

\section{COMMENT}

Neochordal replacement is gaining popularity for mitral valve repair and has shown excellent long-term results. ${ }^{1,2}$ However, determination of the proper length of the neochordae and tying them without knot slipping remain the main challenges encountered. To address these issues, several different modifications have been described. ${ }^{3,4}$

Garcia Fuster and colleagues ${ }^{5}$ reported a modified technique in which the neochord sutures were woven into the prolapsing segment from the free margin to the middle of the leaflet, surpassing the line of coaptation, rather than being sutured onto the free edge of the leaflet. The neochordal lengths were then determined by temporally suturing the leaflet to the adjacent annulus, based on the principle that the length of the marginal chord is equal to that of the basal chord. Such weaving of the leaflet produces a "hockey-stick" effect, thus enlarging the coaptation area and preventing systolic anterior motion. 

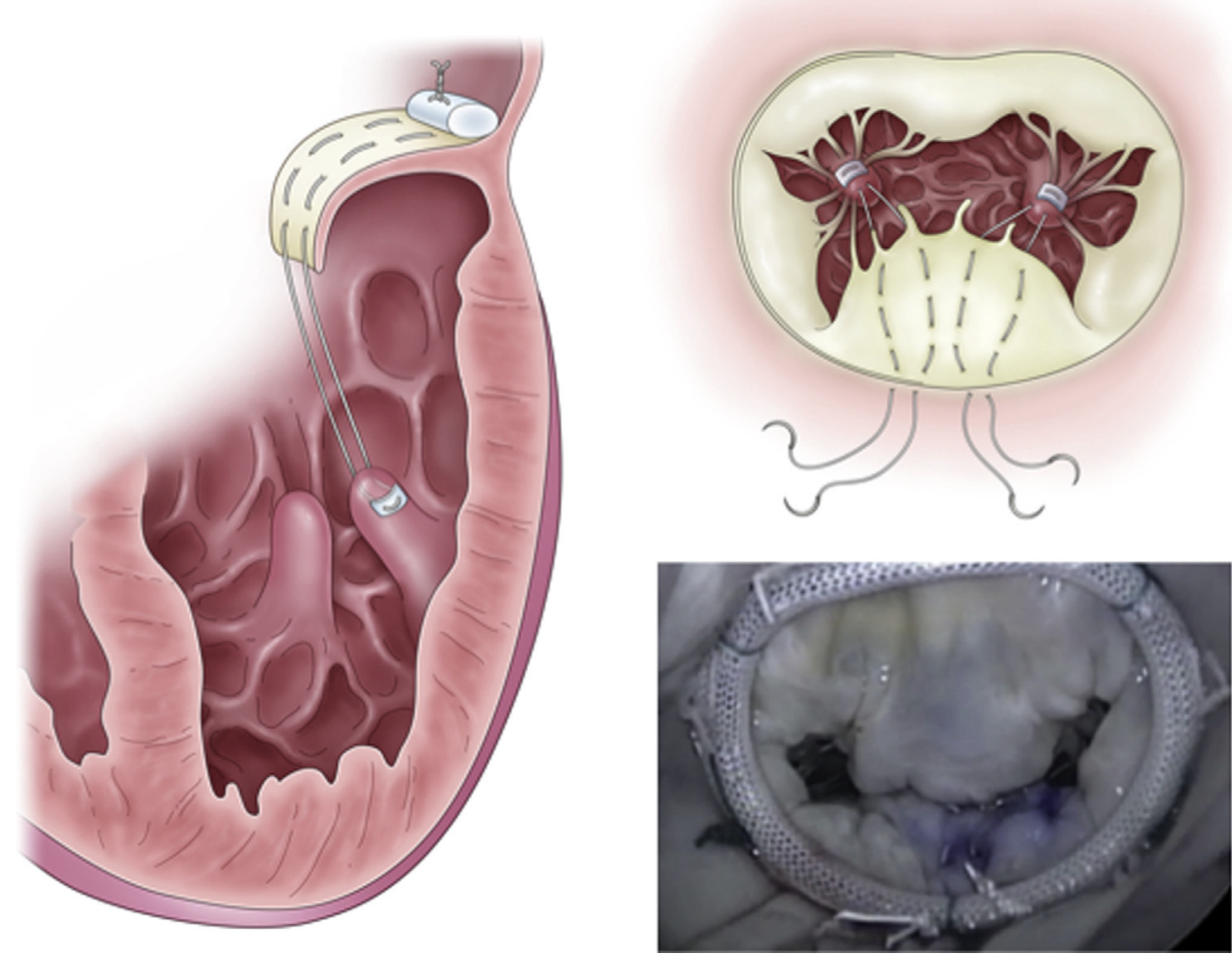

FIGURE 1. e-PTFE neochordae are woven into the prolapsing segment of the mitral valve leaflet and tied onto the annuloplasty ring.

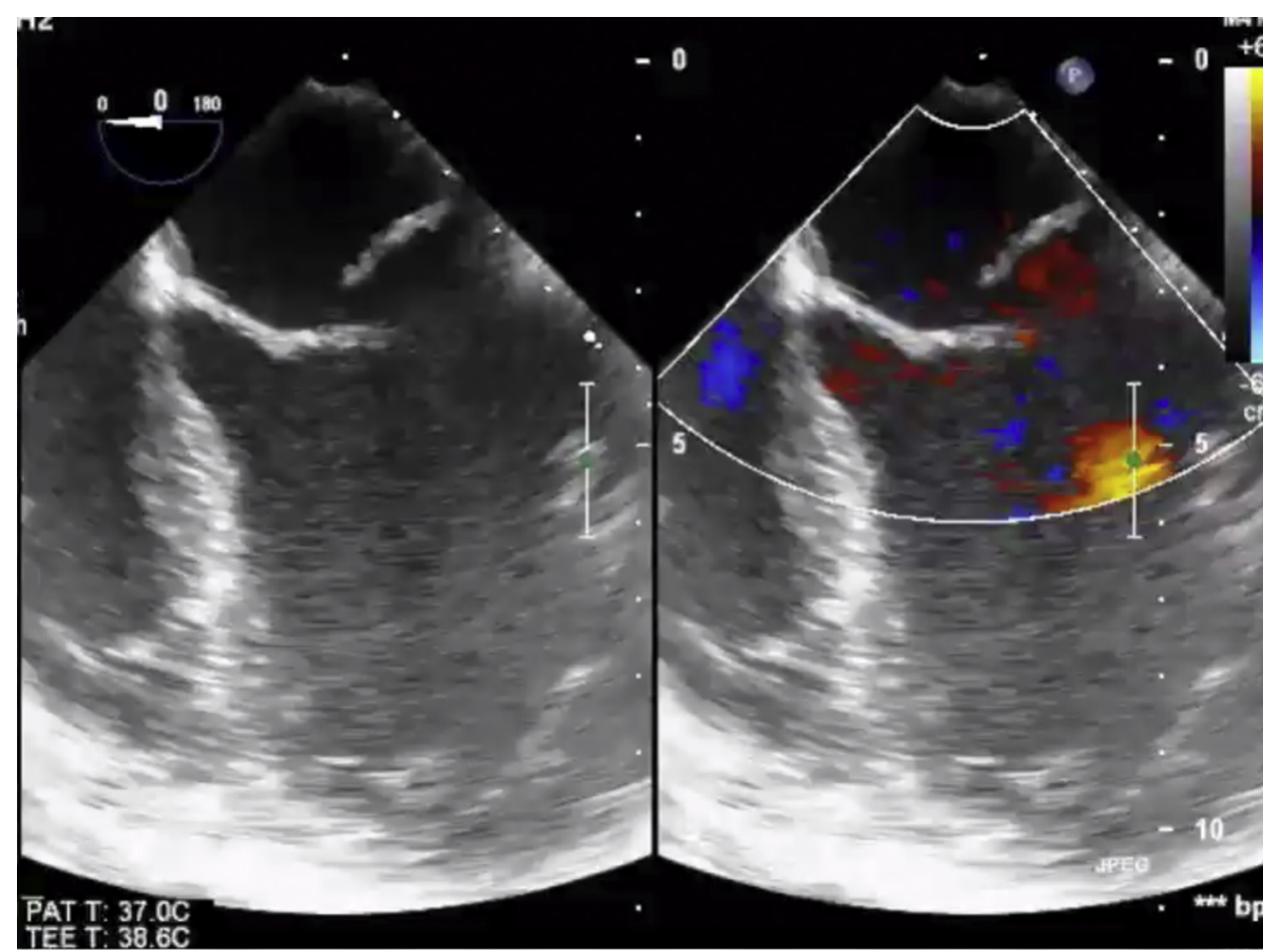

VIDEO 1. Our extended neochord weaving technique for isolated P2 prolapse. The neochordae length is adjusted after placement of the annuloplasty ring with the ventricle pressurized with water. Valve competence can be visually confirmed during knot tying. Case 1: Representative isolated neochord replacement. Case 2: Representative combined leaflet resection and neochord replacement. Video available at: http://www.jtcvsonline.org/article/S0022-5223(16)31036-4/addons. 
Our technique is different from theirs in that the ePTFE sutures are woven until reaching the mitral annulus and secured after passing through the annuloplasty ring, and we believe that it has several advantages. First, leaving the sutures untied at the papillary muscle allows the 2 arms of the neochord to be adjusted to equal lengths and tension, and then weaving the neochordae with multiple bites distributes tension over a wider area of the leaflet. In addition, tying the sutures onto the annuloplasty ring further reinforces the leaflet geometry and prevents tearing of the tissue. Preservation of annulopapillary continuity through the e-PTFE sutures contributes to prevent progressive leaflet prolapse. Second, passing the e-PTFE sutures through the annuloplasty ring creates greater resistance when adjusting the neochordal length, contributing to easy tying without knot slipping. There is no need for clips or a right angle clamp to hold the sutures in place. Furthermore, by tying the sutures onto the annuloplasty ring with the ventricle pressurized with water, the competence of the valve can be visually confirmed during knot tying. Third, with our technique, the knot is located away from the bloodstream flowing through the mitral valve orifice. Eliminating any knots near the coaptation zone may prevent risk of hemolysis caused by possible future recurrent mitral regurgitation.

Ten patients with isolated posterior leaflet prolapse underwent our technique, of whom 4 received isolated neochordal replacement. The other 6 patients underwent combined neochordal replacement with limited resection, which we consider to be especially useful for cases with large or nonuniform prolapse, because that combi- nation allows for correction of prolapse while maintaining adequate leaflet volume. Most of our patients had isolated P2 prolapse, except for 1 with a P3 lesion. Despite initial concerns that the leaflets might become immobile because of our technique to weave the sutures or a tendency to slide along them like a curtain, thus reducing the coaptation area, postoperative echocardiography findings have revealed moderately preserved leaflet motion without such curtain effects or systolic anterior motion. None of the present patients developed significant mitral regurgitation during the initial 6-month follow-up period. Presently, we do not use this technique for cases with anterior leaflet prolapse because of the potential risk of reduced leaflet mobility, which may have a greater influence on repair durability than posterior leaflet repair. Additional clinical follow-up examinations are necessary.

\section{References}

1. David TE, Armstrong S, Ivanov J. Chordal replacement with polytetrafluoroethylene sutures for mitral valve repair: a 25-year experience. J Thorac Cardiovasc Surg. 2013;145:1563-9.

2. Tabata M, Kasegawa H, Fukui T, Shimizu A, Sato Y, Takanashi S. Long-term outcomes of artificial chordal replacement with tourniquet technique in mitral valve repair: a single-center experience of 700 cases. J Thorac Cardiovasc Surg. 2014; 148:2033-8.

3. Ibrahim M, Rao C, Athanasiou T. Artificial chordae for degenerative mitral valve disease: critical analysis of current techniques. Interact Cardiovasc Thorac Surg. 2012;15:1019-32.

4. Jacobs S, Sundermann SH. Minimally invasive valve sparing mitral valve repair - the loop technique - how we do it. Ann Cardiothorac Surg. 2013;2: 818-24.

5. Garcia Fuster R, Martin E, Paredes F, Mena A, Canovas S, Gil O, et al. Artificial chordae in the setting of complex mitral valve repair: early outcomes using the folding leaflet technique. Interact Cardiovasc Thorac Surg. 2014;18: 586-95. 